\title{
Komparasi Criteria Splitting Pada Algoritma Iterative Dichotomizer 3(ID3) Untuk Klasifikasi Kelayakan Kredit
}

\author{
Nandya Ayu Fatmandini ${ }^{1}$, Rizal Amegia Saputra ${ }^{2}$, Resti Yulistria ${ }^{3}$ \\ ${ }^{1}$ Universitas Bina Sarana Informatika \\ e-mail: afinandya@gmail.com \\ ${ }^{2}$ Universitas Bina Sarana Informatika \\ e-mail: rizal.rga@bsi.ac.id \\ ${ }^{3}$ Universitas Bina Sarana Informatika \\ e-mail: resti.res@bsi.ac.id
}

\begin{abstract}
Credit is a form of business run by banks and leasing. In carrying out credit, banks and leasing always pay attention to credit risk that will occur, for that historical data about lending to customers will greatly assist in giving decisions by banks and leasing, this can reduce credit risk. Bank Sinarmas Sukabumi is one of the largest finance companies in Indonesia, this company provides financing services for the purchase of new or used vehicles, several obstacles and obstacles experienced by Bank Sinarmas Sukabumi in terms of credit, one of them is the provision of credit, for that credit analysis is very important, because one of the reasons for the occurrence of bad loans can be caused by lack of accuracy in providing credit companies. ID3 algorithm is one of the best algorithms, the application of ID3 algorithm can predict customer credit worthiness. The purpose of this study is the application of the ID3 method by comparing the three criteria for determining lending, the results of this research experiment revealed that the Information Gain criterion has an accuracy value of $62.67 \%$ and an AUC value of 0.800, the highest of the criteria being compressed, followed by the Gain Ratio criteria and Gini Index has the lowest Accuracy and AUC values. Thus, the ID3 method with the Information Gain criteria, is a good method and criteria in predicting credit granting to Bank Sinarmas Sukabumi customers.
\end{abstract}

Keywords: Comparison of Criteria Splitting, Algortima ID3, Credit Worthiness Classification.

\section{PENDAHULUAN}

Pada saat ini kegiatan kredit sangatlah ramai, hal ini tampak pada pesatnya berkembang perusahaanperusahaan yang menawarkan jasa pembiayaan bagi calon nasabah dalam memenuhi suatu kebutuhannya (Rifqo \& Wijaya, 2017). Dalam dunia perbankan keberadaan kredit merupakan hal yang tak lepas dari salah satu bentuk usaha yang di jalankan. Dalam menjalankan kredit, bank akan selalu memperhatikan resiko kredit yang akan terjadi dalam hal pemberian kredit, untuk itu data tentang penentuan kelayakan kredit akan sangat diperlukan guna menunjang roda bisnis kehidupan perbankan(Harlina, 2018).

Analisa pemberian kredit dilakukan untuk mengevaluasi nasabah atau debitur berdasarkan data historis(Akbilgic \& Bozdogan, 2015). Hal ini dapat mengurangi resiko kredit yang telah menjadi isu yang paling penting dalam dunia industri perbankan, karena akan merugikan terhadap kelangsungan keuangan suatu negara dan berpotensi menimbulkan kesulitan keuangan(Bahri, 2017).

Bank Sinarmas Sukabumi adalah salah satu perusahaan pembiayaan terbesar di Indonesia. Perusahaan ini menyediakan pelayanan pembiayaan untuk pembelian kendaraan baru ataupun kendaraan bekas, sebagai salah satu perusahaan yang bergerak dalam bidang sewa guna usaha (leasing) atau sering disingkat SGU adalah kegiatan pembiayaan dalam bentuk penyediaan barang modal baik secara sewa guna usaha dengan hak opsi (finance lease) maupun sewa guna usaha (lessee) selama jangka waktu tertentu berdasarkan pembayaran secara angsuran, Bank Sinarmas juga mengalami kendala dan hambatan dalam hal perkreditan, pemberian kredit sangatlah berisiko karena dari sekian banyak nasabah yang mengajukan aplikasi kredit ada kemungkinan beberapa pelanggan yang bermasalah dalam pembayaran(Rifqo \& Wijaya, 2017), untuk itu analisa kredit sangatlah penting, karena dapat mengurangi resiko macetnya kredit.

Klasifikasi data kredit pada pihak debitur merupakan tugas penting dalam memprediksi resiko kredit (Iriadi, 2013), bahkan dapat membantu pihak debitur dalam mengambil keputusan resiko kredit, dengan demikian sangat penting melakukan analisa resiko kredit berdasarkan data historis, agar dapat mengurangi resiko kredit. Banyak peneliti yang sudah melakukan kegiatan dalam klasifikasi kelayakan kredit dengan metode klasifikasi data mining, namun belum diketahui metode apa yang paling akurat dalam klasifikasi tersebut.

Penelitian tentang kelayakan kredit sudah banyak dilakukan oleh peneliti sebelumnya, seperti penelitian yang dilakukan Sitti Harlina tahun 2018 dengan judul : "Data Mining Pada Penentuan Kelayakan Kredit Menggunakan Algoritma K-Nn Berbasis Forward Selection" dengan tingkat akurasi 68,30\% (Harlina, 2018), penelitian selanjutnya dilakukan oleh Rifqo dan Wijaya tahun 2017 dengan judul : "Implementasi Algoritma Naive Bayes 
Dalam Penentuan Pemberian Kredit" dengan tingkat akurasi $80 \%$, penelitian selanjutnya dilakukan oleh Marco dan Hidaya tahun 2014 dengan judul "Implementasi Data Mining Untuk Klasifikasi Nasabah Kredit Bank"X" Menggunakan Classification Rule " dengan tingkat akurasi $89,18 \%$ (Rifqo \& Wijaya, 2017).

Algoritma Iterative Dichomtomizer 3 (ID3) merupakan algoritma decision tree learning (algoritma pembelajaran pohon keputusan) yang paling dasar". Algoritma ini melakukan pencarian secara menyeluruh pada semua kemungkinan semua keputusan. Pembentukan pohon klasifikasi dengan algoritma ID3 melalui dua langkah, yaitu menghitung nilai entropy dan menghitung nilai information gain dari setiap variabel (Ispriyanti \& Hoyyi, 2016). Salah satu kelebihan dari algoritma ID3 ini adalah metode pohon keputusan dapat menghindari munculnya permasalahan ini dengan menggunakan kriteria yang jumlahnya lebih sedikit pada setiap node internal tanpa banyak mengurangi kualitas keputusan yang dihasilkan. Oleh sebab itu penelitian ini menggunakan metode ID3 (Itrative Dichotomizer 3), dengan Algoritms ID3 ini dapat memberikan data yang lengkap sehingga akan lebih dipermudah bagi pihak bank untuk menentukan dalam pemberian kelayakan kredit.

\section{METODOLOGI PENELITIAN}

Tahapan penelitian dalam penulisan skripsi pemberian kredit dapat digambarkan pada bagan berikut ini:

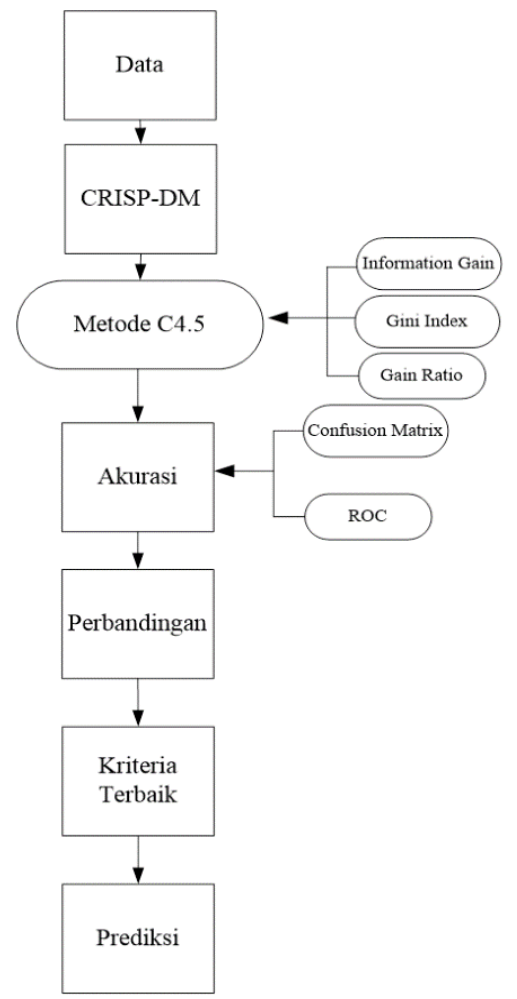

Gambar .1. Bagan Tahapan Penelitian
Berdasarkan gambar tahapan penelitian diatas dapat dijelaskan sebagai berikut:

1. Data mentah di reduksi terlebih dahulu dan dimasukan ke dalam Microsoft Excel untuk menjadi data tranning, total data yang dikumpulkan 100 data.

2. Dengan menggunkan metode CRISP - DM data diolah untuk menghilangkan duplikasi, yang sudah tersedia pada software RapidMiner 5.2, data dari hasil penghapusan duplikasi data menjadi 54 data.

3. Selanjutnya data di uji dengan menggunakan Algoritma ID3 dengan mengkomparasi tiga kriteria yaitu Gini Index, Gain Ratio dan Information Gain untuk mendapatkan validasi dari data tersebut.

4. Data validasi kemudian diuji dengan Confusion Matrix dan ROC untuk mendapatkan akurasi terbaik dari tiga kriteria.

5. Kemudian rule pohon keputusan hasil dari pengolahan algoritma ID3 tersebut, dapat dijadikan untuk memprediksi pemberian kredit lancar dan macet.

Dalam penelitian ini menggunakan metode eksperimen dengan model Cros Industry Standard Process for Data Mining (CRISP-DM) yang terdiri dari 6 tahap, yaitu(Pattipeilohy et al., 2017):

1. Business/Research Understanding Phase Berdasarkan dari data kredit terdapat 100 data yang didapat dari tahun 2018, data dapat dilihat pada lampiran 1 untuk dapat mempecepat penyeleksian harus dilakukan pemeriksaan terhadap data-data yang dikumpulkan, hal ini dapat dibantu dengan memanfaatkan teknik klaisifikasi pada data mining model ID3.

2. Data Understanding Phase (Fase Pemahaman Data)

Data yang digunakan adalah data sekunder, yang didapat dari Bank Sinarmas Sukabumi, didalam data tersebut dapat diketahui lancar dan macet pemberian kredit yang terdiri dari 7 atribut predictor dan 1 atribut hasil. Atributatribut yang menjadi parameter terlihat pada tabel 1 .

Tabel .1.Atribut dan kategori lancar dan macet pemberian kredit

\begin{tabular}{ll}
\hline Atribut & Kategori \\
\hline Jenis Kelamin & L \\
& P \\
\hline Jenis Pekerjaan & Wiraswasta \\
& PNS \\
& skilled \\
& Swasta \\
& management \\
\hline Jumlah Pinjaman & $1.000 .000-$ \\
& 10.000 .000 \\
& $10.000 .000-$ \\
& 25.000 .000 \\
\hline Jangka Waktu Pengembalian & $>25.000 .000$ \\
\hline
\end{tabular}




\begin{tabular}{ll}
\hline & Pendek \\
Paminan & Panjang \\
\hline Pengh Mobil \\
& BPKP Motor \\
& Sertifikat \\
\hline Riwayat_kredit & $1-5$ Juta \\
& $6-10$ Juta \\
& $>11$ Juta \\
\hline Kesimpulan & Baik \\
& Cukup \\
& Buruk \\
& Baik Sekali \\
\hline & Lancar \\
& Macet
\end{tabular}

3. Tahapan data persiapan (Data Preparation) Berdasarkan data latih yang diperoleh, maka sebelum pemodelan dilakukan, diperlukan beberapa teknik pre-processing yang digunakan, yaitu:

a. Data Validation

Untuk mengidentifikasi dan menghapus data yang ganjil (outlier/noise), data yang tidak konsistensi dan data yang tidak lengkap (missing value).

b. Data integration and transformation

Untuk meningkatkan akurasi dan efisiensi algoritma. Data yang digunakan dalam penulisan ini bernilai kategorikal.

c. Data size reduction and dicretization

Untuk memperoleh data set dengan jumlah aribut dan record yang lebih sedikit tetapi bersifat informatif. Proses penghapusan data duplikasi menggunakan software RapidMiner. Setelah dilakukan pengidentifikasian serta menghapus dan menggabungkan beberapa data yang lengkap maupun tidak lengkap juga dilakukan reduction and dicretization untuk pengujian data.

4. Tahapan pemodelan (Modelling)

Tahap ini juga disebut tahap learning karena pada tahap ini data diklasifikasikan oleh model dan kemudian menghasilkan sejumlah aturan. Pada penelitian ini, pembuatan model menggunakan algoritma ID3

5. Tahap evaluasi (Evaluation)

Pada tahap ini dilakukan pengujian terhadap model-model untuk mendapatkan informasi model yang akurat. Evaluasi dan validasi menggunakan metode Confision Matrix dan Kurva ROC.

6. Tahap Deployment

Pada tahap ini diterapkan model yang relevan untuk penyeleksian data calon nasabah kredit pada Bank Sinarmas Sukabumi.

\section{HASIL DAN PEMBAHASAN}

\section{Hasil Eksperimen dan Pengujian Model}

Berikut adalah gambar pengujian Algoritma ID3 menggunakan Framework RapidMiner versi 3:
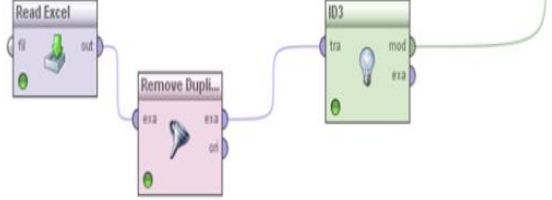

Gambar 2. Desain Model ID3 Pada RapidMiner

Sehingga jika model tersebut dijalankan maka akan didapatkan hasil pohon keputusan seperti gambar 3 dibawah ini:

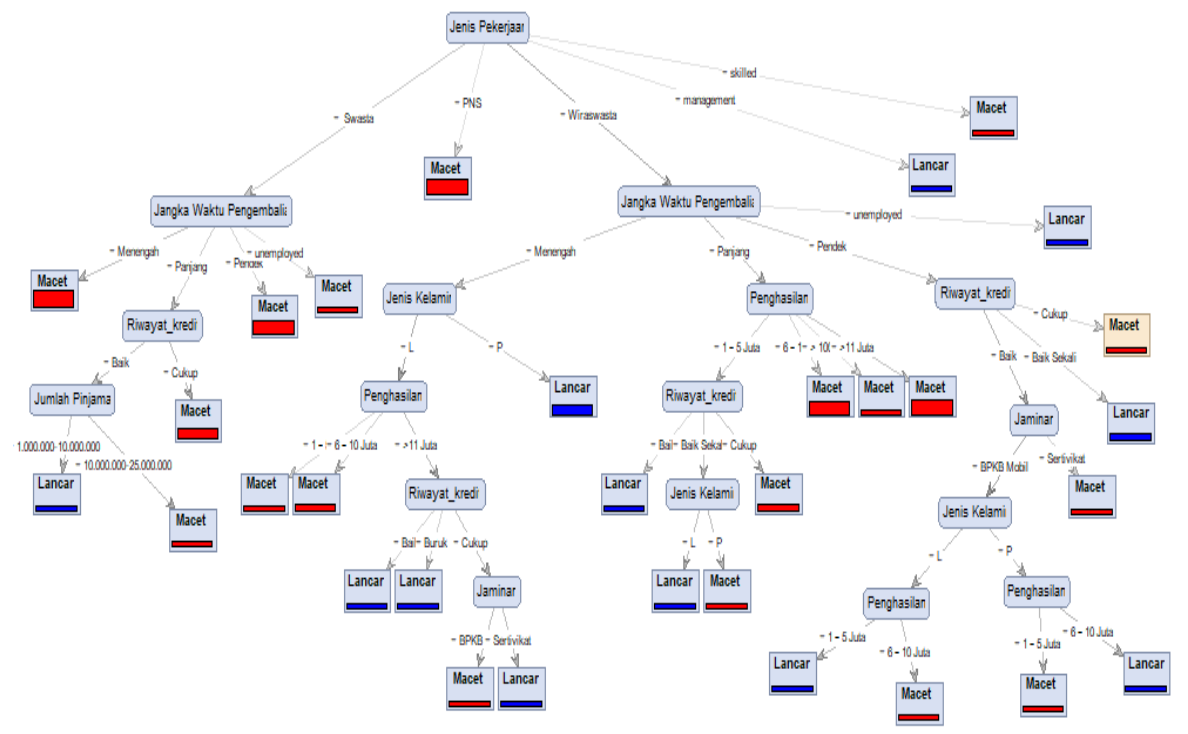

Gambar 3. Pohon Keputusan Pemberian Kredit 
Tujuan utama dari menganalisis data dengan menggunakan algoritma ID3 ini yaitu ingin mendapatkan rule(Saputra, 2014), dimana rule tersebut akan dimanfaatkan untuk pengambilan keputusan pada data baru. Rule ini akan didapat berdasarkan dari model pada gambar 4 sebagai berikut:

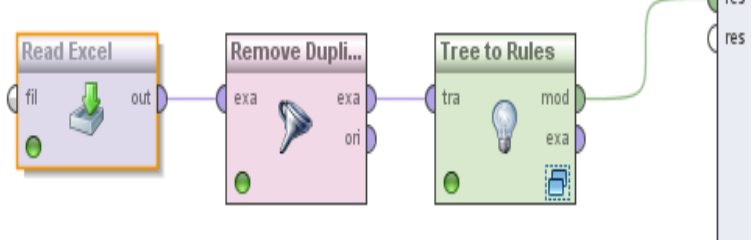

Gambar 4. Desain Model Rule Algoritma ID3

Pada gambar 4 diatas maka diperoleh aturan -aturan sebagai berikut:

1) if Jenis Pekerjaan = Swasta and Jangka Waktu Pengembalian $=$ Menengah then Macet

2) if Jenis Pekerjaan = Swasta and Jangka Waktu Pengembalian $=$ Panjang and Riwayat_kredit $=$ Baik and Jumlah Pinjaman $=1.000 .000-$ 10.000.000 then Lancar

3) if Jenis Pekerjaan = Swasta and Jangka Waktu Pengembalian $=$ Panjang and Riwayat_kredit $=$ Baik and Jumlah Pinjaman $=10.000 .000-$ 25.000.000 then Macet

4) if Jenis Pekerjaan = Swasta and Jangka Waktu Pengembalian $=$ Panjang and Riwayat_kredit $=$ Cukup then Macet

5) if Jenis Pekerjaan = Swasta and Jangka Waktu Pengembalian $=$ Pendek then Macet

6) if Jenis Pekerjaan = PNS and Jangka Waktu Pengembalian $=$ Menengah and Jenis Kelamin $=$ L then Lancar

7) if Jenis Pekerjaan = PNS and Jangka Waktu Pengembalian $=$ Menengah and Jenis Kelamin $=$ $\mathrm{P}$ and Penghasilan $=1-5$ Juta then Macet

8) if Jenis Pekerjaan = PNS and Jangka Waktu Pengembalian = Menengah and Jenis Kelamin = $\mathrm{P}$ and Penghasilan $=6-10$ Juta then Lancar

9) if Jenis Pekerjaan = PNS and Jangka Waktu Pengembalian $=$ Panjang then Macet

10) if Jenis Pekerjaan = Wiraswasta and Jangka Waktu Pengembalian $=$ Menengah and Jenis Kelamin $=\mathrm{L}$ and Penghasilan $=1-5$ Juta then Macet

11) if Jenis Pekerjaan = Wiraswasta and Jangka Waktu Pengembalian $=$ Menengah and Jenis Kelamin $=\mathrm{L}$ and Penghasilan $=6-10$ Juta then Macet

12) if Jenis Pekerjaan = Wiraswasta and Jangka Waktu Pengembalian $=$ Menengah and Jenis Kelamin $=\mathrm{L}$ and Penghasilan $=>11$ Juta and Riwayat_kredit $=$ Baik then Lancar

13) if Jenis Pekerjaan = Wiraswasta and Jangka Waktu Pengembalian $=$ Menengah and Jenis
Kelamin $=\mathrm{L}$ and Penghasilan $=>11$ Juta and Riwayat_kredit $=$ Buruk then Lancar

14) if Jenis Pekerjaan = Wiraswasta and Jangka Waktu Pengembalian $=$ Menengah and Jenis Kelamin $=\mathrm{L}$ and Penghasilan $=>11$ Juta and Riwayat_kredit $=$ Cukup and Jaminan $=$ BPKB Mobil then Macet

15) if Jenis Pekerjaan = Wiraswasta and Jangka Waktu Pengembalian $=$ Menengah and Jenis Kelamin $=\mathrm{L}$ and Penghasilan $=>11$ Juta and Riwayat_kredit $=$ Cukup and Jaminan = Sertifikat then Lancar

16) if Jenis Pekerjaan = Wiraswasta and Jangka Waktu Pengembalian $=$ Menengah and Jenis Kelamin $=\mathrm{P}$ then Lancar

17) if Jenis Pekerjaan = Wiraswasta and Jangka Waktu Pengembalian $=$ Panjang and Penghasilan $=1-5$ Juta and Riwayat_kredit = Baik then Lancar

18) if Jenis Pekerjaan = Wiraswasta and Jangka Waktu Pengembalian $=$ Panjang and Penghasilan $=1-5$ Juta and Riwayat_kredit = Baik Sekali and Jenis Kelamin = L then Lancar

19) if Jenis Pekerjaan = Wiraswasta and Jangka Waktu Pengembalian $=$ Panjang and Penghasilan $=1-5$ Juta and Riwayat_kredit $=$ Baik Sekali and Jenis Kelamin $=\mathrm{P}$ then Macet

20) if Jenis Pekerjaan = Wiraswasta and Jangka Waktu Pengembalian $=$ Panjang and Penghasilan $=1-5$ Juta and Riwayat_kredit = Cukup then Macet

21) if Jenis Pekerjaan = Wiraswasta and Jangka Waktu Pengembalian $=$ Panjang and Penghasilan $=6-10$ Juta then Macet

22) if Jenis Pekerjaan = Wiraswasta and Jangka Waktu Pengembalian $=$ Panjang and Penghasilan $=>11$ Juta then Macet

23) if Jenis Pekerjaan = Wiraswasta and Jangka Waktu Pengembalian $=$ Pendek and Riwayat_kredit $=$ Baik and Jaminan $=$ BPKB Mobil and Jenis Kelamin $=\mathrm{L}$ and Penghasilan = 1 - 5 Juta then Lancar

24) if Jenis Pekerjaan = Wiraswasta and Jangka Waktu Pengembalian $=$ Pendek and Riwayat_kredit $=$ Baik and Jaminan $=$ BPKB Mobil and Jenis Kelamin $=\mathrm{L}$ and Penghasilan $=$ 6 - 10 Juta then Macet

25) if Jenis Pekerjaan = Wiraswasta and Jangka Waktu Pengembalian $=$ Pendek and Riwayat_kredit $=$ Baik and Jaminan $=$ BPKB Mobil and Jenis Kelamin $=\mathrm{P}$ and Penghasilan $=$ $1-5$ Juta then Macet

26) if Jenis Pekerjaan = Wiraswasta and Jangka Waktu Pengembalian $=$ Pendek and Riwayat_kredit $=$ Baik and Jaminan $=$ BPKB Mobil and Jenis Kelamin $=\mathrm{P}$ and Penghasilan $=$ 6 - 10 Juta then Lancar

27) if Jenis Pekerjaan = Wiraswasta and Jangka Waktu Pengembalian $=$ Pendek and 
Riwayat_kredit $=$ Baik and Jaminan $=$ Sertifikat then Macet

28) if Jenis Pekerjaan = Wiraswasta and Jangka Waktu Pengembalian $=$ Pendek and Riwayat_kredit $=$ Baik Sekali then Lancar

29) if Jenis Pekerjaan = Wiraswasta and Jangka Waktu Pengembalian $=$ Pendek and Riwayat_kredit $=$ Cukup then Macet

30) if Jenis Pekerjaan = management then Lancar

31) if Jenis Pekerjaan = skilled then Macet

\section{Evaluasi dan Validasi}

Dalam penelitian ini metode yang digunakan yaitu ID3, kemudian dilakukan komparasi dari tiga kriteria pada algoritma ID3, ketiga kriteria tersebut dipilih mana yang paling besar dalam akurasinya. Metode klasifikasi bisa dievaluasi berdasarkan beberapa kriteria seperti tingkat akurasi, kecepatan, kehandalan, skalabilitas, dan interpretabilitas(Saputra, 2014).

\subsection{Pengujian Model}

1. Model Confusion Matrix

Tabel 2. Komparasi Nilai Akurasi

\begin{tabular}{lccc}
\hline & $\begin{array}{c}\text { Gain } \\
\text { Ratio }\end{array}$ & $\begin{array}{c}\text { Information } \\
\text { Gain }\end{array}$ & Gini Index \\
\hline Accuracy & $60,67 \%$ & $62,67 \%$ & $55,33 \%$ \\
\hline
\end{tabular}

Berdasarkan Tabel 2. diatas tersebut menunjukan bahwa metode ID3 dengan kriteria Information Gain memiliki akurasi yang tinggi dibandingkan dengan kriteria yang lainnya yaitu sebesar $62,67 \%$.

Selain nilai accuracy, akan dihitung juga nilai sensitivity, specificity, $p p v$, dan $n p v$, sebagai contoh untuk mencari nilai accuracy, sensitivity, specificity, $p p v$, dan $n p v$ pada hasil perhitungan metode ID3 dengan Information Gain dengan persamaan dibawah ini:

Accuracy $=0,62963$
Sensitivity $=0,4$
Specificity $=0,764706$
PPV $=0,5$
NPV $=0,684211$

2. Model Kurva ROC

Pebandingan hasil perhitungan nilai AUC untuk metode ID3 dengan tiga kriteria yaitu Gain Ratio, Information Gain, Gini Index dapat dilihat pada Tabel 3.

Tabel 3. Komparasi Nilai AUC

\begin{tabular}{cccc}
\hline & $\begin{array}{c}\text { Gain } \\
\text { Ratio }\end{array}$ & Information Gain & $\begin{array}{c}\text { Gini } \\
\text { Index }\end{array}$ \\
\hline AUC & 0,733 & 0,800 & 0,698 \\
\hline
\end{tabular}

Tabel 3. menunjukan bahwa hasil nilai AUC yang paling tinggi, yaitu pada nilai $\mathbf{0 , 8 0 0}$, dan dapat dikategorikan klasifikasi Baik, dikarenakan memiliki nilai diantara 0.80 - 0.90 (Saputra,RA.2014).

\subsection{Deployment}

Berikut tampilan GUI yang dibuat pada penelitian ini:

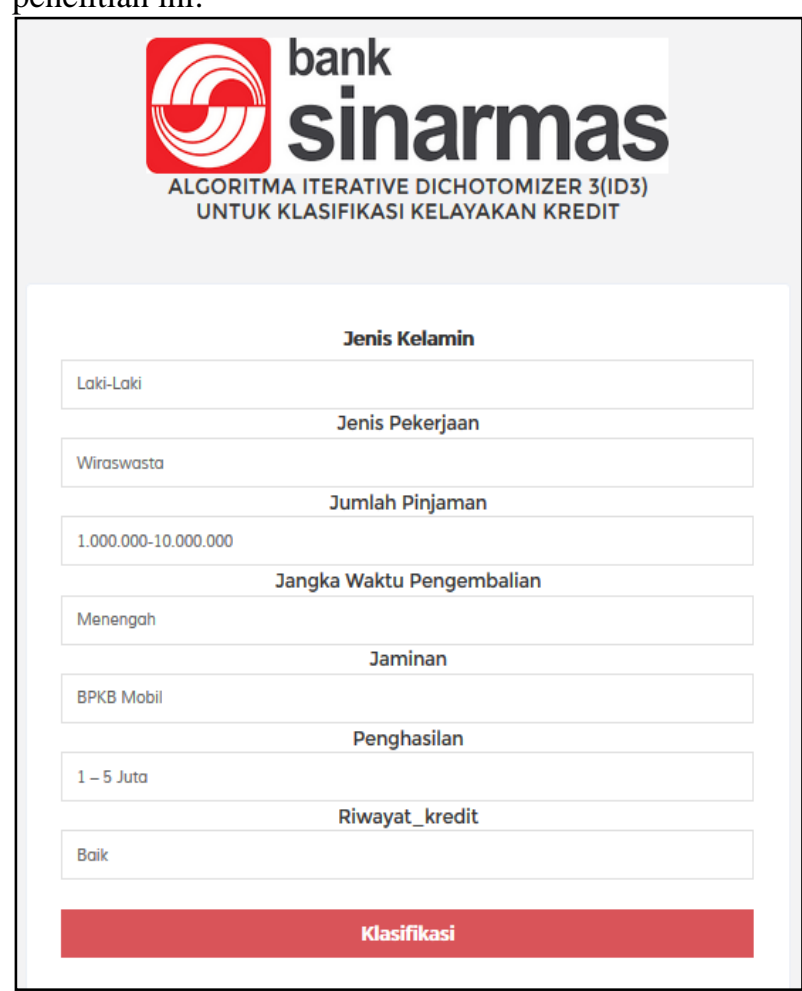

Gambar 5. Form Klasifikasi Kelayakan Kredit Dengan Algoritma ID3

Gambar 5. menggambarkan GUI untuk klasifikasi penentuan pemberian kredit dengan hasil lancar dan macet

\section{KESIMPULAN}

Berdasarkan pembahasan pada bab-bab sebelumnya, dapat diambil kesimpulan dari penerapan metode ID3 dengan membanding tiga kriteria untuk penentuan pemberian kredit, diketahui bahwa kriteria Information Gain memiliki nilai accuracy dan AUC paling tinggi diantara kriteria yang dikomprasikan, diikuti dengan kriteria Gain Ratio dan Gini Index memiliki nilai Accuracy dan AUC paling rendah. Dengan demikian, metode ID3 dengan kriteria Information Gain, merupakan metode dan kriteria yang baik dalam memprediksi pemberian kredit pada nasabah Bank Sinarmas Sukabumi

\section{Saran}

Agar penelitian ini bisa ditingkatkan, berikut adalah saran-saran yang diusulkan:

a. Hasil penelitian ini diharapkan dapat digunakan pada Bank Sinarmas, untuk lebih meningkatkan efesiensi dan kecepatan dalam pengambilan suatu keputusan pada nasabah.

b. Menambahkan jumlah data yang lebih besar dan atribut yang lebih banyak, sehingga hasil pengukuran yang akan didapatkan lebih baik lagi. 
c. Melakukan pengembangan dengan feature selection, untuk menyeleksi atribut yang berpengaruh kuat, sehingga atribut yang dipakai hanya sedikit namun tidak mengurangi akurasi dari algoritma yang digunakan.

d. Penelitian ini dapat dikembangkan dengan membandingkan algoritma data mining lainnya atau dapat mengoptimalkan parameter dengan Particle Swarm Optimization, Genetic Algorithm dan lainnya.

e. Grapic User Interface (GUI) perlu dikembangkan mengikuti kemajuan IPTEK, Seperti GUI yang berbasis mobile computing atau aplikasi yang didukung oleh android dan yang lainnya.

\section{REFERENSI}

Akbilgic, O., \& Bozdogan, H. (2015). A New Supervised Classification of Credit Approval Data via the Hybridized RBF Neural Network Model Using Information Complexity. In Data science, learning by latent structures, and knowledge discovery. In Spinger (Vol. 48). Spinger. https://doi.org/10.1007/978-3-66244983-7

Bahri, S. (2017). Seleksi Atribut Pada Algoritma C4.5 Menggunakan Genetik Algoritma Dan Bagging Untuk Analisa Kelayakan Pemberian Kredit. Klik - Kumpulan Jurnal Ilmu Komputer, 4(2), 174. https://doi.org/10.20527/klik.v4i2.99

Harlina, S. (2018). Data Mining Pada Penentuan Kelayakan Kredit Menggunakan Algoritma KNn Berbasis Forward Selection Data Mining on Credit Feasibility Determination Using $\mathrm{K}-\mathrm{Nn}$ Algorithm Based on Forward Selection. 11(2), 236-244.

Iriadi, N. (2013). Komparasi Algoritma Klasifikasi Data Mining Dalam Penentuan Resiko Kredit Pada Koperasi Serba Usaha. Paradigma, XV(2).

Ispriyanti, D., \& Hoyyi, A. (2016). Analisis Klasifikasi Masa Studi Mahasiswa Prodi Statistika Undip dengan Metode Support Vector Machine (SVM) dan ID3 (ITERATIVE DICHOTOMISER 3). Media Statistika, 9(1), 15-29. https://doi.org/10.14710/medstat.9.1.15-
29

Pattipeilohy, W. F., Wibowo, A., \& Utari, D. R. (2017). Pemodelan Dan Prototipe Sistem Informasi Untuk Prediksi Pembaharuan Polis Asuransi Mobil Menggunakan Algoritma C.45. Seminar Nasional Teknologi Dan Informatika 2017 (SNATIF), October, 791-799. https://www.neliti.com/id/publications/173500/p emodelan-dan-prototipe-sistem-informasiuntuk-prediksi-pembaharuan-polis-asuran

Rifqo, M. H., \& Wijaya, A. (2017). Implementasi Algoritma Naive Bayes Dalam Penentuan Pemberian Kredit. Jurnal Pseudocode, 4(2), 120-128. https://doi.org/10.33369/pseudocode.4.2.120128

Saputra, R. A. (2014). Komparasi Algoritma Klasifikasi Data Mining Untuk Memprediksi Penyakit Tuberculosis ( $\mathrm{Tb}$ ): Studi Kasus Puskesmas Karawang. Seminar Nasional Inovasi Dan Tren (SNIT), April, 1-8.

Tyasti, A. E., Ispriyanti, D., \& Hoyyi, A. (2015). Algoritma Iterative Dichotomiser 3 (ID3) Untuk Mengidentifikasi Data Rekam Medis (Studi Kasus Penyakit Diabetes Mellitus Di Balai Kesehatan Kementerian Perindustrian, Jakarta). Jurnal Gaussian, 4, 237-246.

\section{PROFIL PENULIS}

Rizal Amegia Saputra, M.Kom, Lulus S-1 tahun 2010, Jurusan Sistem Informasi, STMIK Nusa Mandiri Sukabumi. Lulus S-2 tahun 2013, Program Studi Ilmu Komputer, Pasca Sarjana, STMIK Nusa Mandiri Jakarta. Sekarang menjadi Dosen di Universitas Bina Sarana Informatika PSDKU Sukabumi.

Resti Yulistria, S. Pd, MM, Lulus S-1 tahun 2009, Program Studi Pendidikan Manajemen Perkantoran, Fakultas Ekonomi dan Bisnis, Universitas Pendidikan Indonesia. Lulus S-2 tahun 2011, Program Studi Magister Manajemen Bisnis, Pasca Sarjana, Universitas Pendidikan Indonesia. Sekarang menjadi Dosen di Universitas Bina Sarana Informatika PSDKU Sukabumi. 